\title{
CAN SOUND OVERCOME CHALLENGES AND BOOST STUDENTS CREATIVITY?
}

\author{
Danah ALHUSSAIN ${ }^{1}$, John COUNSELL ${ }^{2}$, Nick PERHAM ${ }^{2}$ and Jon PIGOTT ${ }^{2}$ \\ ${ }^{1}$ Immam Abdulrahman Bin Faisal University, Saudi Arabia \\ ${ }^{2}$ Cardiff Metropolitan University, United Kingdom
}

\begin{abstract}
Some HE institutions restrict students' choice of where to work which, in addition to students being in shared non-ideal environs, reduce their personal control over the physical factors of such spaces. This thrusts students into situations where they are required to be creative within challenging environs. Research shows an important role music plays in learning process which is determined by the complexity of task conducted while music played. This paper investigates personal private sound control via headsets, as a key element used by students in inadequate learning environs, to mitigate the perceived deficiencies of such environs; referred to as soundscapes. It analyses the result of an experiment conducted with number of design students from Immam Abdulrahman university (IAU) in Saudi Arabia as a form of Design Charrette. This Charrette was designed to investigate the effect of exposing participants by wearing headset to five different sound conditions on their creativity while completing a design task (Design a tool). The assessment was by a Design Jury with selected Jury members are experts in the field of design to evaluate the work. The result of the experiment showed that sound affects the individual's perception of their performance, possibly more than it affects their actual performance. That effect on perception could lead to better creative performance if utilized in proper way in educational spaces. This will outline plans for further investigation as part of a current $\mathrm{PhD}$ research project.
\end{abstract}

Keywords: Creativity, physical environs, Charrette, design, creative, assessment, sound, soundscape, condition

\section{INTRODUCTION}

Students wish to change their surroundings to allow them to cope with the inadequacy of their learning environs. Yet, the possibilities of modifying these environs may be limited, either because: a move to other environs is too expensive or time-consuming; or are not permissible. Therefore, students use personal private sound control via headsets, to mitigate the perceived deficiencies of such environs which referred to as "Soundscape".

In 1934, the term 'muzak' was coined by Wired Radio Inc., which began to deliver ambient music to commercial clients [1]. Muzak refers to the background music used in public spaces which, it is claimed, will improve individuals' mood, increase productivity among employees, or stimulate consumers' need to make a purchase $[1,2]$. Research into learning environments has stated that background music can be useful in creating a positive learning environment that assists students' task persistence and productivity. Students have differing musical preferences; therefore, it is important for the teacher to use the appropriate type of music [3]. Thirty years ago, broadcast background music was the only option available for students to feel motivated in such educational spaces, since headphones were attached to computers and other electronic devices, which were considered heavy and were not portable [4]. The production of affordable and portable sound devices, such as the Sony Walkman in 1979, provided the option to use sound to alter the current environs with a transition to the use of electronic personal devices $[4,5]$.

\section{SOUND, MOOD AND AROUSAL, ARE THEY RELATED?}

Some researchers have investigated the effect of sonic environs on individuals and how it reflects upon their creativity. For example, Ritter and Ferguson [6] examined silence, its role in increasing attention and focus and how, in return, that increases creativity. It has been argued that natural sounds (such as 
birds, waterfalls, rain) boost pupils' creativity and performance within the art classroom setting [7;8]. Hilton et al. [9] argued that music can have a positive effect on performance and creativity when played at a low volume.

One of the most famous examples of how music affects performance is the "Mozart effect" which argued that listening to music by Mozart prior to conducting a task increases abilities such as spatial abilities in comparison to other sound conditions. This is more commonly referred to now as mood and arousal effect which some researchers studied how this reflects upon creativity and performance. Arousal refers to "the degree of physical and psychological activation" [6], while mood refers to the indication of whether an emotion is positive or negative. For example, Chablis et al. [9] claimed that being in silence or listening to relaxation music relates to an increased arousal. It is argued that a positive mood reflects positively on productivity and creativity [10]. This could be explained by how different types of music create different moods; the music then reflects on the creativity as shown in the study of Yamada and Nagai [11]. In their study, they conducted experiments to compare listening to happy music with listening to a reading of the Japanese constitution ('sad music') while conducting a creative task of generating new names for rice. The result of the study showed significant improvement in the creative solutions proposed while listening to the happy music compared to the 'sad music'.

Irrelevant sound effect (ISE) is explored by auditory distraction researchers as an effect that happens when listening to music before conducting the task, contrasted with concurrent (happening at the same time as doing the task and ignoring it). Perham and Vizard [12] showed ISE to have a negative effect on performance. Further studies have shown that whether ISE affects performance either positively or negatively depends on the type of task conducted [13].

The effects of sound exposure on creativity were the focus of Ritter and Ferguson's [6] study. Each participant was exposed to five concurrent soundscape conditions while required to list and name as many creative and new uses of a commonly used object as possible. The sound conditions applied in that study as: calm (positive valance, low arousal); happy (positive valance, high arousal); sad (negative valance, low arousal); anxious (negative valance, high arousal); silence (no music induction). The study was divided into different tasks with breaks between them. Participants were informed of the task process prior to start with music played for 15 seconds before participant start of the task to allow them to 'get into' the music. Participants were students recruited via the Radboud University online participation system (Sona); they were not selected for creativity. They were rewarded for participation by either a course credit of 0.5 hours or $5 €$ (in Iris cheques). A survey of the mood level of each participant was conducted to evaluate the mood before and during each sound condition using a 7-point Likert scale ranging from 1 (not at all) to 7 (very much). The result of their study suggests that listening to happy music increases mood and arousal and, in return, this is reflected in the individual's overall divergent thinking and creativity. They questioned if the preference for music or prior knowledge of the playlist and/or the task might be reflected differently in the result. They claimed that listening to music could be a positive method for promoting creative thinking when it is needed in scientific, educational, and organizational settings. They also proposed to investigate natural sound effects (i.e., rain, forests, wind) for future studies. Although they showed an effect of sound on performance and creativity, the scenarios they employ has participants perform the task in quiet situations or silence, whereas much of the time we perform these tasks with sound in the background.

A link between arousal level (activating vs. deactivating), mood, and creativity was suggested by De Dreu et al [14] by exploring how activating moods (positive arousal) can influence the fluency and originality of the creative performance, arguing that a positive mood enhances cognitive flexibility yet a negative mood enhanced persistence. It is argued that music itself is not the effective factor for productivity and creativity, as claimed by the so-called Mozart effect. In fact, the enhancement is linked to the "enjoyment arousal" that the music creates within individuals [15].

Thus said, this research is addressing the relationship proposed between sound and creativity, and how by controlling the personal soundscape in learning environs, students claim to produce more creative work when been freely allowed to choose this soundscape. Participants in this experiment (Design students) were asked to perform 5 different design tasks in 5 different sound conditions and were expected to perform more creatively in situation where they were free to choose the sound condition or at least liked that sound condition. 


\section{METHODOLOGY}

Experimental research has been shown to be a valuable method of both quantitively and qualitatively evaluating design artefacts and approaches and examining the relationship between independent and dependent variables [16]. In this research, the independent variable was the Soundscape and the dependent variable, the participants' creativity which were calculated based on the evaluation of experts in the field as form of Jury members (a form of evaluation used in design fields such as Architecture). the aim here is that through the experimental method a more explicit understanding of the relationship between these variables could be drawn [17].

'Design Charrette' is an architectural term, referring to the creative study of a design issue by a team of designers within a limited time frame. It is "a type of co-design workshop for the purpose of developing creative solutions to a specific design problem within a limited time frame" [18]. This study argues that its use, will help explore the hypothesis that there is a relationship between sound and creativity in learning environs. Participants: 20 Participants (Design students from IAU) were tasked to complete the design tasks within 6 hours (Including breaks and evaluation of work by Jury members). This charrette was a themed competition called Life on Kepler 452-b. The concept is to design survival tools for survivors on Kepler from earth. An overview of the experiment is shown in Figure 1.
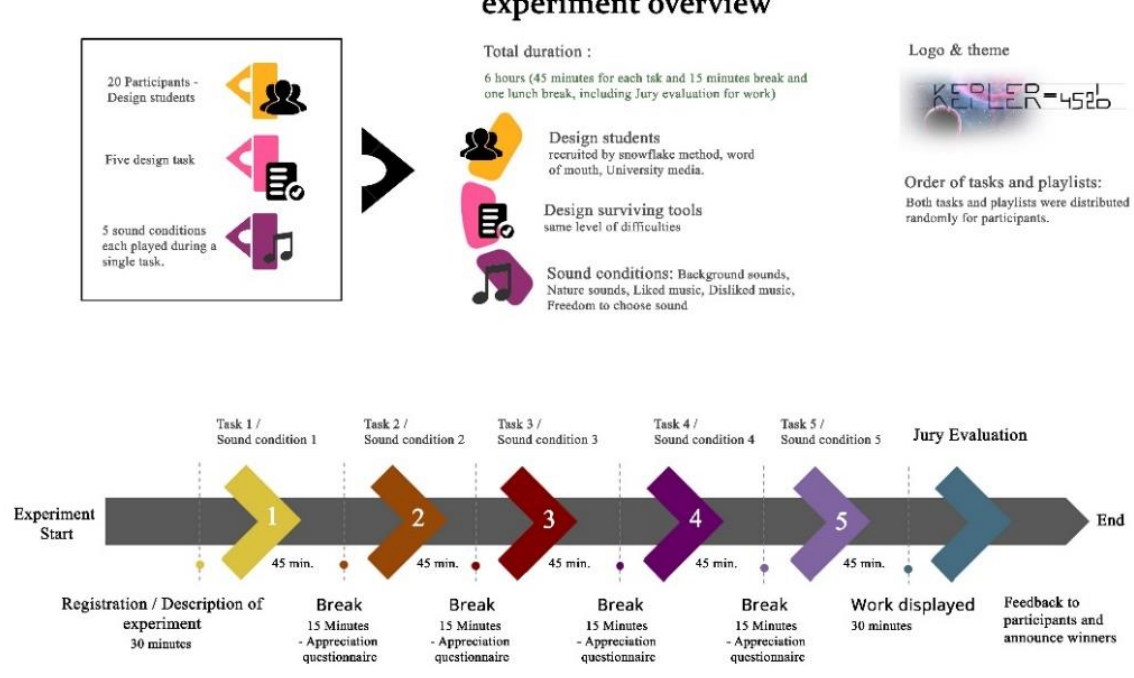

Figure 1. Experiment outline

Task: previous experiment conducted by Alhussain et al. [19], found that the type of task to include in the experiment must be at an appropriate level of challenge and be interesting for the participants. Also, because this research aims to inform improvements of the physical learning environs, the task should relate to a 'real-life' design student learning process. Therefore, the task proposed was a simple problemsolving design task (design survival tool) for each participant to complete. Task sheets were randomly distributed to participants with a pre-selected choice of sound condition assigned for each task. This was so that different tasks would be conducted during different sound conditions using their own headsets. The quality of the drawings was not the main factor in the evaluation; rather, the important factor was the quality of the idea itself and following the rules and guidelines for each task as shown in figure 2. The level of difficulty of the task was set by the researcher based on the researcher's experience working as a teacher assistant/lecturer since 2011.

Playlists were created by the researcher on Soundcloud (an online audio distribution platform) based on trending tracks in each category at the time on social media. These playlists were then distributed to participants with the instruction to listen and rank the playlist from Best to Worst based on their preferences. They were also asked to bring a playlist of their choice. In this study, detailed instructions of why or how these playlists will be used during the experiment were not given to participants.

The different sound conditions were chosen based on sounds used in other studies, which were confirmed as playing a critical role through interviews with the design students conducted prior to the experiment. They claimed that liked/disliked music plays a critical role when they are conducting a task. They also stated that freedom of choice about what to play was reflected strongly in their creative outcome. Some also mentioned how silence is their ideal sound condition for creative tasks. Others claimed that sounds from nature, such as rain, waves, and forest sounds, help them feel more relaxed and, in return, more creative. As a result, the following sound conditions were chosen: 
Liked/ Disliked sound: a SoundCloud list extracted from a set of playlists (Pop music, Heavy metal, Classical music, foreign language) for that the participants ranked from best to worst prior to the Charrette, without them being informed of the reason behind this ranking. These playlists were created based on their popularity in social media and a questionnaire to similar age groups as the participants.

Nature: This included sounds from nature such as rain, waves and forest.

Freedom of choice: The participant could choose from the playlist provided by the researcher or select their own preferred playlist.

Background: As total silence is achievable only in laboratories and pre-set environs, the background sound of ambient coffee shop noise was the closest choice for the physical environs in everyday life which claimed by some research to boost creativity [20]. Each participant experienced these five sound conditions while conducting the design tasks, not all playlists presented to participants should be played, except for nature and background which is required for each participant.

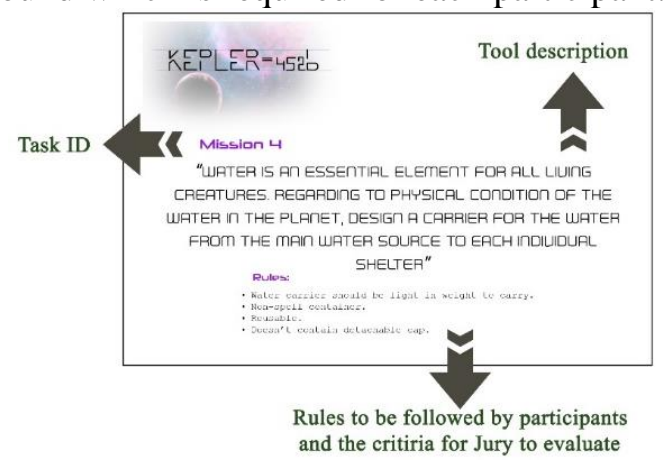

Figure 2. Task card overview

Between each task, 15 min break were given to participants to complete a subjective ratings questionnaire of the sound condition and evaluate their performance. Questions were investigating levels of arousal and mood in forms of concentrating/relaxation, alertness and pleasantness. Questions about well concentration/relaxation were asked beside questions about whether it was hard to concentrate/relax during each task. Questionnaire was as a form of 9 points Likert scale (1 lowest- 9 Highest). These data were later analysed using one-way ANOVA in compared with the evaluation from the jury members. Participants who finished all five tasks and questionnaires were eligible to enter the competition and the chance to win the top 3 prizes: SR300 (Saudi Riyals) gift card for first place, SR 200 for second place, and SR 150 for third place. When the tasks were completed, participants were asked to hang their work in the gallery area for the evaluation process.

\subsection{Evaluation of creativity}

In order to establish a more realistic experience for the students and to introduce an objective evaluation of their creative performance under different sound conditions, the results were judged by a design jury with the work anonymously distributed in the gallery (only the competition unique ID was on the presented work for the jury). The evaluation criteria to the jury members were:

- Fulfil all the design criteria for the survival tool/complete all 5 survival tool design tasks.

- $\quad$ Complied with the required design process.

- Created a tool that is useful and novel.

A total mean grade was given to each student after evaluation of each task separately by the jury members. As the jury members' backgrounds and points of view were different, they settled on a process of giving each task one grade agreed by all jury members.

\section{ANALYSIS OF THE RESULTS}

In this study, an analysis of variance (ANOVA) was conducted to study the difference in means between sound conditions and the effect on concentrating, relaxing, alertness, and pleasantness. Although the sample size may be considered small, within designs like this using a similar sample size have been used to explore auditory distraction in papers published in high impact journals such as Jones \& Macken [21], and Hughes et al. [23].

\section{Appreciation questionnaire analysis:}

The following analyses (Figure 3) focus on the appreciation questionnaire was conducted by participants which showed that: 
- Participants felt they had concentrated effectively in the Freedom and Best conditions compared to other conditions with a significant main effect of sound rating, $\mathrm{F}(4,76)=10.67$, MSE $=4.19, \mathrm{p}<$ $.001, \eta 2 p=.36$. Whilst they found Worst and the Background conditions as the most difficult to concentrate with rating $\mathrm{F}(4,76)=5.12, \mathrm{MSE}=6.09, \mathrm{p}<.001, \eta 2 \mathrm{p}=.21$.

- higher levels of relaxation in the Freedom and Best conditions compared to those in the Background and Worst conditions, with no significant different in the Nature condition as shown in the following rating $\mathrm{F}(4,76)=23.87, \mathrm{MSE}=4.05, \mathrm{p}<.001, \eta 2 \mathrm{p}=.56 . \mathrm{F}(4,76)=23.87$, MSE $=4.05, \mathrm{p}<.001, \mathrm{\eta} 2 \mathrm{p}=.56$. It was hard to relax in the Worst and Background conditions. It rated $\mathrm{F}(4,76)=8.76, \mathrm{MSE}=7.05, \mathrm{p}<.001, \eta 2 \mathrm{p}=.32$.

- $\quad$ higher levels of alertness in the Freedom sound condition rating, $F(4,76)=10.02$, MSE $=5.70, p$ $<.001, \eta 2 p=.35$. Also, pleasantness levels are Freedom and Top conditions with rating $F(4,76)$ $=10.67, \mathrm{MSE}=4.19, \mathrm{p}<.001, \mathrm{\eta} 2 \mathrm{p}=.36$.

- The Jury evaluation (following Bonferroni adjustments) showed that participants scored marginally higher in the Nature condition, more than in the other conditions $(p<.05)$.

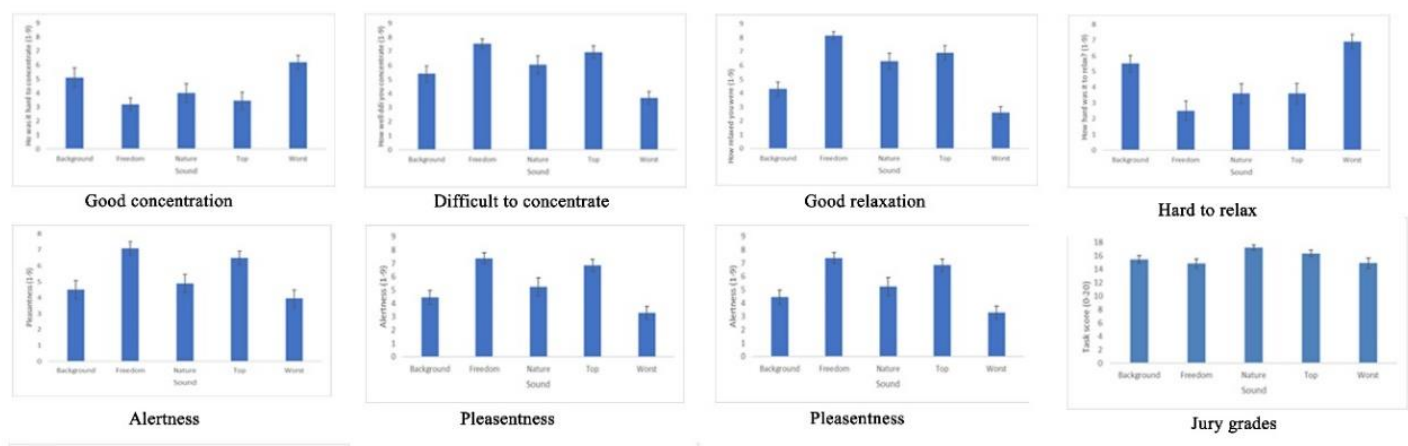

Figure 3. Means and standard errors of concentration/relaxation/Alertness/pleasantness and evaluation by sound conditions

\section{DISCUSSION AND CONCLUSION}

The aim of the study was to examine the claim by students that using their personal headphones with a personalized soundscape allows them to overcome any inadequacy of the physical environs and produce creative work. Yet the result shows that sound affects the individual's perception of their performance, possibly more than it affects their actual performance. As in Ritter and Ferguson's study [6], participants scored Freedom sound condition as the best to increase both arousal and mood in comparison to other sound conditions. Yet, Freedom sound condition achieved the lowest score (alongside the worst condition) evaluated by the Jury members in compared to Nature sound condition. This finding raises more questions relating to the research. For example, this difference in the evaluation could be due to the soundscape but could also relate to the different level of experience between the two groups, and how they applied the system of evaluation in terms of work being 'novel' and 'useful' and meeting particular criteria. Such points also raise more general questions of subjectivity in design evaluation as the average evaluation system led to a similar range of grades for the five different conditions.

Although instructions about the experiment were distributed among participants prior to the experiment day through emails, some participants did not go through the instructions until introduced again the day of the experiment. As a result, some claimed that the playlists they chose did not reflect the ones they would use during the production of the creative work. This could have affected the results, and the evaluation of each phase and sound condition as well. The idea behind distributing the tasks in a random order was to be sure that each participant would follow their own ideas without being influenced by others around them. Overall, this was successful though did cause some confusion to some participants. This could possibly have affected the outcome of such participants and prevented them from producing to their full creative capacity. In future research, additional experiments could be designed and conducted taking the above limitations into consideration. For example, brief explanation of the concept of the experiment and the theme of the competition should be explained to participants prior to the experiment day. The list of playlists and the ranking instructions would be clarified, and it would be stated that these playlists will be used as a test condition during the experiment which involves conducting creative task. It should also be clear that the experiment will include drawings and using the 
headphones during that. Also, a brief description of each question from the questionnaire could be provided in advance. In terms of jury evaluation, allowing the participants themselves to participate in the evaluation process, might create a different range of evaluation to that of the experts alone. Also, considering a different evaluation structure for the upcoming experiment could reflect differently in the outcome of the evaluation. Re-evaluation of existing results using the new structure could also be beneficial for the sake of comparison.

\section{REFERENCES}

[1] De Jong, S. (2018). Sentimental Education. Sound and Silence at History Museums. Museum and Society, 16(1).

[2] Lanza, J. (2004) Elevator Music. A Surreal History of Muzak, Easy-Listening, and Other Moodsong, Ann Arbor: University of Michigan Press.

[3] Savage, T.V. and Savage, M.K., 2009. Successful classroom management and discipline: Teaching self-control and responsibility. Sage.

[4] Du Gay, P., Hall, S., Janes, L., Madsen, A.K., Mackay, H. and Negus, K., 2013. Doing cultural studies: The story of the Sony Walkman. London: Sage in association with the Open University.

[5] Hagood, M. (2019). Hush. Media and sonic self-control. Durham: Duke University Press.Hennink, M., Hutter, I. and Bailey, A., 2010. Qualitative research methods. Sage.

[6] Ritter, S.M. and Ferguson, S., 2017. Happy creativity: Listening to happy music facilitates divergent thinking. PloS one, 12(9), p.e0182210.

[7] Panuszka K, Panuszka R (2002). 'Effect of noise on social relationships'. The Journal of the Acoustical Society of America, 112(5), pp. 2272-2272.

[8] Alawad, A., 2012. Can we bring the natural environment into the art classroom? Can natural sound foster creativity? Educational Research and Reviews, 7(28), pp.627-631.

[9] Chablis, C. F., Steele, K. M., Dalla Bella, S., Peretz, I., Dunlop, T., Dawe, L. A., et al. (1999). Prelude or requiem for the 'Mozart effect'? Nature, 400, 826-828.

[10] Schellenberg, E. (2005). Music and Cognitive Abilities. Current Directions in Psychological Science, 14(6), pp.317-320.

[11] Yamada Y, Nagai M. Positive mood enhances divergent but not convergent thinking. Japanese Psychological Research, 57(4), pp. 281-287.

[12] Perham, N. and Vizard, J. (2010). Can preference for background music mediate the irrelevant sound effect? Applied Cognitive Psychology, 25(4), pp.625-631.

[13] Threadgold, E., Marsh, J., McLatchie, N. and Ball, L. (2019). Background music stints creativity: Evidence from compound remote associate tasks. Applied Cognitive Psychology.

[14] De Dreu, Carsten KW, Matthijs Baas, and Bernard A. Nijstad. "Hedonic tone and activation level in the mood-creativity link: toward a dual pathway to creativity model." Journal of personality and social psychology 94.5 (2008): p.739.

[15] Taylor, J.M. and Rowe, B.J., 2012. The "Mozart Effect" and the mathematical connection. Journal of College Reading and Learning, 42(2), pp.51-66.

[16] Campbell, D.T. and Stanley, J.C., 2015. Experimental and quasi-experimental designs for research. Ravenio Books.

[17] Zeneli, M., Thurston, A., \& Roseth, C. (2016). The influence of experimental design on the magnitude of the effect size -peer tutoring for elementary, middle and high school settings: A meta-analysis. International Journal of Educational Research, 76, 211-223.

[18] Walker, Jason B., and Michael W. Seymour. "Utilizing the design charrette for teaching sustainability." International Journal of Sustainability in Higher Education (2008).

[19] Alhussain, Danah, Gareth Loudon, and Paul Wilgeroth. "Creativity in product design education: Understanding the learning environment." E\&PDE16, 2016. pp. 102-107.

[20] Lee, Y.S., 2016. Creative workplace characteristics and innovative start-up companies. Facilities.

[21] Jones, D., \& Macken, W. (1995). Phonological similarity in the irrelevant speech effect: Withinor between-stream similarity? Journal of Experimental Psychology: Learning, Memory, And Cognition, 21(1), 103-115. doi: 10.1037/0278-7393.21.1.103

[22] Hughes, R., Marsh, J., \& Jones, D. (2011). Role of serial order in the impact of talker variability on short-term memory: testing a perceptual organization-based account. Memory \& Cognition, 39(8), 1435-1447. doi: 10.3758/s13421-011-0116-x. 